\title{
Bagaimana Kualitas Pelayanan dan Fasilitas Belajar dapat Mempengaruhi Loyalitas Mahasiswa dengan Mediasi Kepuasan Mahasiswa?
}

\author{
Ongen Stembri Pattiwaellapia \\ Universitas Pembangunan Nasional "Veteran” Yogyakarta \\ ongenstembri01@gmail.com
}

\begin{abstract}
This study aims to analyze the effect of service quality and learning facilities on student loyalty mediated by student satisfaction. The subjects of this study were students of the Magister Management of the National Development University "Veteran" Yogyakarta. This research includes a quantitative approach with a survey method. Collecting data in this study using a questionnaire with a Likert scale. The data analysis method used was SmartPLS 3.0. Results 1) The effect of service quality directly has a positive effect on student loyalty by 0.002 but not significant because the $T$-statistic is $0.008<1.96$ and the $P$-value is $=0.994>0.05$. Thus the quality of service does not have a significant effect on student loyalty of Master of Management at the National Development University “Veteran" Yogyakarta. 2) The effect, learning facilities have a positive effect on student loyalty of 0.339 but not significant because the T-statistic is $1.218<1.96$ and the $P$-value is $=0.226>0.05$. Thus, learning facilities do not have a significant effect on the loyalty of students of Master of Management at the National Development University "Veteran" Yogyakarta. 3) Influence, learning facilities have a positive effect on student loyalty by 0.339 but not significant because the T-statistic is $1.218<1.96$ and the P-value is $=0.226>0.05$. Thus, learning facilities do not have a significant effect on the loyalty of students of Master of Management at the 'Veteran' National Development University Yogyakarta. 4) The effect of learning facilities in this case has a positive and significant effect on student loyalty by mediating student satisfaction of 0.192 (T-Statistics = 1.984 and $P$-value $=0.048$ ). The estimation results of the mediation test show that student satisfaction can mediate the effect of learning facilities on student loyalty because the $T$-statistic is greater than 1.96 , namely 1.984 and the $P$-value $=0.048$ is smaller than the P-value 0.05 . It can be interpreted that there is an effect of learning facilities on student loyalty which is mediated by student satisfaction.
\end{abstract}

Keywords- Service Quality, Learning Facilities, Student Satisfaction and Student Loyalty.

\begin{abstract}
Abstrak- Penelitian ini bertujuan untuk menganalisis pengaruh kualitas pelayanan dan fasilitas belajar terhadap loyalitas mahasiswa dimediasi kepuasan mahasiswa. Subyek penelitian ini adalah mahasiswa Magister Manajemen Universitas Pembangunan Nasional 'Veteran' Yogyakarta. Penelitian ini termasuk pendekatan kuantitatif dengan metode survey. Pengambilan data dalam penelitian ini menggunakan kuesioner dengan skala Likert. Metode analisis data yang digunakan adalah SmartPLS 3.0. Hasil penelitian 1) Pengaruh kualitas pelayanan secara langsung berpengaruh positif terhadap loyalitas mahasiswa sebesar 0,002 namun tidak signifikan kare na $T$ statistic 0,008 < 1,96 dan P-value sebesar = 0,994 > 0.05. Dengan demikian kualitas pelayanan tidak berpengaruh signifikan terhadap loyalitas mahasiswa Magister Manajemen Universitas Pembangunan Nasional 'Veteran' Yogyakarta. 2) Pengaruh , fasilitas belajar berpengaruh positif terhadap loyalitas mahasiswa sebesar 0,339 namun tidak signifikan karena $T$-statistik 1,218 $<1,96$ dan $P$-value sebesar $=0.226>0.05$. Dengan demikian fasilitas belajar tidak berpengaruh signifikan terhadap loyalitas mahasiswa Magister Manajemen Universitas Pembangunan Nasional 'Veteran' Yogyakarta. 3) Pengaruh, fasilitas belajar berpengaruh positif terhadap loyalitas mahasiswa sebesar 0,339 namun tidak signifikan karena T-statistik 1,218 $<1,96$ dan P-value sebesar $=0.226>0.05$. Dengan demikian fasilitas belajar tidak berpengaruh signifikan terhadap loyalitas mahasiswa Magister Manajemen Universitas Pembangunan Nasional 'Veteran' Yogyakarta. 4) Pengaruh Fasilitas belajar dalam hal ini berpengaruh positif dan signifikan terhadap loyalitas mahasiswa dengan mediasi kepuasan mahasiswa sebesar 0,192 $(\mathrm{T}$-Statistik $=1,984$ dan P-value $=0,048$ ). Hasil estimasi uji mediasi menunjukkan bahwa kepuasan mahasiswa dapat memediasi pengaruh fasilitas belajar terhadap loyalitas mahasiswa karena $T$-statistik lebih besar dari 1,96 yaitu 1,984 dan P-value =0,048 lebih kecil dari P-value 0,05. Dapat diintepretasikan bahwa ada pengaruh fasilitas belajar terhadap loyalitas mahasiswa yang dimediasi oleh kepuasan mahasiswa.
\end{abstract}

Kata Kunci- Kualitas Pelayanan, Fasilitas Belajar, Kepuasan Mahasiswa dan Loyalitas Mahasiswa.

\section{PENDAHULUAN}

Pendidikan merupakan suatu hal yang terpenting dalam kehidupan sehingga setiap manusia berhak untuk mendapatkannya. Pendidikan adalah sebuah proses belajar terus menerus dalam keseluruhan aktifitas sosial sehingga manusia tetap ada dan berkembang (Brameld, 1992). Daerah Istimewa Yogyakarta (DIY) merupakan salah satu provinsi dari 34 provinsi yang ada di Indonesia. Sebagai ibukota
Provinsi Daerah Istimewa Yogyakarta, Kota Yogyakarta kaya predikat, baik berasal dari sejarah maupun potensi yang ada, seperti sebagai kota perjuangan, kota kebudayaan, kota pelajar, dan kota pariwisata (Dikpora DIY, 2018). Perguruan Tinggi merupakan salah satu penyedia jasa, oleh karena itu, Perguruan Tinggi harus mampu memberikan pelayanan yang terbaik bagi mahasiswanya. Kondisi persaingan yang semakin ketat dalam bidang 
pendidikan saat ini, memaksa setiap Perguruan Tinggi ataupun penyelenggara pendidikan tinggi harus memberikan pelayanan yang terbaik serta berbeda dengan para pesaing.

Loyalitas pelanggan di dunia pendidikan dikenal sebagai loyalitas mahasiswa. Loyalitas mahasiswa sangat diperlukan untuk kelangsungan hidup dan eksisnya suatu Perguruan Tinggi. Mahasiswa yang memiliki loyalitas tinggi merupakan aset Perguruan Tinggi karena akan menyampaikan hal positif dan merekomendasi teman, saudara maupun masyarakat lain untuk menggunakan jasa pendidikan yang telah dialaminya (Zeithaml dkk, 1996). Salah satu kondisi yang dihadapi dunia pendidikan tinggi Indonesia saat ini merupakan masalah persaingan antar Perguruan Tinggi. Dari data Statistik Pendidikan Perguruan Tinggi Kementerian Pendidikan Nasional menyebutkan jumlah Perguruan Tinggi di Indonesia menunjukkan perkembangan cukup pesat. Untuk tahun 2009/2010 Perguruan Tinggi Swasta yang ada di Indonesia berjumlah 2892 dan Perguruan Tinggi Negeri berjumlah 83. Sedangkan jumlah Perguruan Tinggi tahun 2017/2018 yaitu sebesar 4.586, yang terdiri 400 Perguruan Tinggi Negeri dan 4.186 Perguruan Tinggi Swasta. Data tersebut menunujukan bahwa jumlah Perguruan Tinggi yang ada di Indonesia mengalami peningkatan yang cukup pesat di 8 tahun terakhir.

Kondisi ini menuntut komitmen dari Perguruan Tinggi untuk dapat memenuhi harapan mahasiswanya. Hal ini diperlukan agar dapat memenangkan persaingan dengan Perguruan Tinggi lain yang kian bertambah. Pengelola lembaga pendidikan sebagai salah satu bentuk perusahaan jasa tidak boleh berfikir bahwa pelayanan jasa yang ditawarkannya tanpa memperhatikan apa yang diinginkan oleh mahasiswanya akan diminati. Universitas Pembangunan Nasional "Veteran" Yogyakarta (UPN "Veteran" Yk) merupakan salah satu Universitas Negeri di Yogyakarta yang turut merasakan persaingan tersebut. Sehingga, agar dapat memenangkan persaingan dengan Perguruan Tinggi lain pihak Perguruan Tinggi harus melakukan upaya untuk mendapatkan dan memenuhi harapan mahasiswanya. Salah satu Fakultas di UPN "Veteran" Yk yaitu Fakultas Ekonomi dan Bisnis.

Pada penelitian ini difokuskan pada program studi Magister Manajemen Universitas Pembangunan Nasional "Veteran" Yogyakarta (MM UPN "Veteran" Yk). Dalam upaya agar MM UPN "Veteran" Yk tetap bertahan dan semakin berkembang serta mempunyai berbagai keunggulan, maka yang perlu dilakukan adalah memberikan pelayanan terbaik untuk memenuhi kebutuhan mahasiswa. (Selnes, 1993) menyatakan loyalitas mahasiswa mencerminkan niatan berperilaku (intended behavior) berkenaan dengan suatu layanan jasa pendidikan. Niatan berperilaku di sini mencakup seberapa mungkin mahasiswa tidak akan beralih ke penyedia layanan jasa pendidikan lainnya. Hal ini berarti pelayanan terbaik yang diberikan oleh penyedia jasa pendidikan menjadikan suatu persepsi yang positif dimata mahasiswa yang kemudian dapat menimbulkan kepuasan bagi mahasiswa tersebut sehingga terbentuknya loyalitas. Mendapatkan mahasiswa yang loyal, adalah salah satu kunci keberhasilan jasa pendidikan atau dalam hal ini menjadi tolak ukur kesuksekan sebuah Perguruan Tinggi.

Berdasarkan wawancara dengan beberapa mahasiswa di MM UPN "Veteran" Yk, maka hasil yang diperoleh adalah keinginan mereka untuk berkuliah di MM UPN "Veteran" Yk dipengaruhi oleh dua faktor yakni pertama melalui informasi pada media elektronik (internet), dan kedua yang dianggap sebagai faktor utama adalah melalui ajakan teman yang terlebih dahulu berkuliah pada MM UPN "Veteran" Yk. Hal ini membuktikan bahwa mahasiswa MM UPN "Veteran" Yk telah memiliki rasa loyalitas terhadap MM UPN "Veteran" Yk untuk merekomendasikan orang lain berkuliah di MM UPN "Veteran" Yk. Kepuasan mahasiswa dipersepsikan sebagai sikap mahasiswa yang diperoleh setelah mengalami pengalaman educational (Elliott dan Healy, 2001), atau dapat dipersepsikan sebagai evaluasi subjektif mahasiswa berdasarkan pengalamannya dengan edukasi dan kehidupan kampus (Elliot dan Shin, 2002). Kepuasan mahasiswa akan terwujud jika apa yang diterima atau dialami oleh mahasiswa tersebut sesuai dengan apa yang diharapkannya. (Zeithmal dan Bitner 2003).

\section{KAJIAN PUSTAKA}

\section{Pemasaran dan Manajemen Pemasaran}

Amstrong (2003) mendefinisikan pemasaran sebagai proses sosial dan manajerial dimana individu dan kelompok memperoleh apa yang mereka butuhkan dan inginkan melalui penciptaan dan pertukaran produk serta nilai dengan pihak lain. Selain itu, dalam pemasaran diperlukan suatu cara untuk mengatur proses pertukaran yaitu manajemen pemasaran.

Menurut Tjiptono (2002), manajemen pemasaran adalah proses perencanaan dan pelaksanaan konsepsi penentuan harga, promosi dan distribusi barang, jasa dan gagasan untuk menciptakan 
pertukaran dengan kelompok sasaran yang memenuhi tujuan pelanggan dan organisasi. Berdasarkan definisi tersebut di atas dapat disimpulkan bahwa manajemen pemasaran adalah suatu kegiatan yang sangat kompleks untuk mencapai tujuan pelanggan dan organisasi.

\section{Loyalitas Mahasiswa \\ Definisi Loyalitas Mahasiswa}

Dari sisi dunia pendidikan, mahasiswa akan diposisikan sebagai pihak yang harus dilayani sedemikian rupa agar kepuasan tercipta karena pelayanan yang telah diberikan, dimana dalam menciptakan kepuasan mahasiswa tidak akan terlepas dari norma-norma pendidikan. Kebanyakan dari Perguruan Tinggi tidak mengetahui bahwa loyalitas mahasiswa dapat dibentuk melalui beberapa tahapan, mulai dari mencari calon mahasiswa potensial sampai dengan advocate customers (para mahasiswa yang ikut menyuarakan almamater) yang jelas sekali akan membawa dampak positif bagi Perguruan Tinggi tempat mahasiswa tersebut berasal (Chan, 2017).

\section{Indikator Loyalitas Mahasiswa}

Tujuan akhir keberhasilan Perguruan Tinggi menjalin hubungan relasi dengan mahasiswanya adalah untuk membentuk loyalitas yang kuat. Berikut ini merupakan indikator dari loyalitas yang kuat menurut Zeithaml dkk (1996) :

1. Say positive things, adalah mengatakan hal yang positif tentang perguruan tinggi.

2. Recommend a friend, adalah mahasiswa akan merekomendasikan perguruan tinggi kepada teman.

Loyalitas dalam dunia pendidikan khususnya di Perguruan Tinggi adalah merupakan komitmen positif dari mahasiswa terhadap jasa pendidikan yang dialaminya selama menempuh perkuliahan.

\section{Kualitas Pelayanan}

\section{Definisi Kualitas Pelayanan}

Kualitas pelayanan sebagai refleksi persepsi evaluatif konsumen terhadap pelayanan yang diterima pada suatu waktu tertentu. (Parasuraman, 1988). Kualitas pelayanan didefinisikan sebagai penilaian mahasiswa atas keunggulan atau keistimewaan suatu layanan jasa pendidikan secara menyeluruh (Zeithaml, 2001).

Kualitas jasa pendidikan di perguruan tinggi secara ringkas memiliki 5 dimensi untuk meningkatkan loyalitas mahasiswa yaitu: tampilan/wujud, kehandalan, daya tanggap, empati dan jaminan (kepastian). (Parasuraman, 1988). Dengan kata lain mahasiswa merupakan salah satu pelanggan yang harus dilayani dengan baik dengan kualitas pelayanan berkualitas sehingga perguruan tinggi dapat eksis.

\section{Dimensi Kualitas Pelayanan}

Menurut Parasuraman (1988) Sebuah skala beberapa item yang digunakan untuk mengukur kualitas pelayanan yaitu menggunakan 5 dimensi serqual diantaranya: keandalan, ketanggapan, jaminan, empati, dan bukti fisik.
a. Keandalan (Reliability)
b. Ketanggapan (Responsiveness)
c. Empati (Empathy)
d. Bukti fisik (Tangibles)

\section{Fasilitas Belajar \\ Pengertian Fasilitas Belajar}

Menurut Gie (2002) dalam bukunya Cara Belajar yang Efisien, "untuk belajar yang baik hendaknya tersedia fasilitas belajar yang memadai, antara lain ruang belajar yang baik, perabotan belajar yang tepat, perlengkapan belajar yang efisien”. Jadi prinsipnya fasilitas belajar adalah segala sesuatu yang memudahkan untuk belajar. Definisi konseptual fasilitas belajar adalah peralatan dan perlengkapan yang secara langsung dipergunakan dan menunjang proses pendidikan, khususnya proses belajar mengajar. (Geta, 2017).

\section{Indikator Fasilitas Belajar}

Oemar Hamalik (2003) Fasilitas yang secara umum dapat mempengaruhi sebuah kegiatan belajar serta dapat membantu proses kelancaran belajar diantaranya adalah:

a. Ruang Belajar. Secara ideal menurut Oemar Hamalik (2003) Ruang belajar harus memenuhi persyaratan sebagai berikut:

1) Pencahayaan serta ventilasi yang baik

2) Jauh dari hiruk-pikuk jalan raya atau keramaian kota

3) Menjaga kebersihan, kerapihan dan keindahan ruangan agar ruangan sedap dipandang mata.

4) Lingkungan tertib dan ama

5) Menciptakan situasi ruang belajar yang nyaman

6) Ukuran ruang cukup memadai untuk kegiatan belajar

7) Cat tembok, meski tergolong sesuatu yang bersifat subjektif namun hendaknya pemilihan warna jangan yang bersifat mencolok.

8) Atur ruangan agar serasi terhadap penempatan meja dan kursi serta peralatanperalatan lain.

b. Alat Bantu Belajar dan Media Pengajaran 
Bentuk-bentuk media yang digunakan untuk meningkatkan pengalaman belajar agar menjadi kongkrit. Penggunaan media tidak lain adalah untuk mengurangi verbalisme agar anak mudah mengerti bahan pelajaran yang disajikan.

Beberapa jenis media yang dapat digunakan dalam proses belajar antara lain:

1) Media audio

2) Media proyeksi

c. Perpustakaan

Menurut Gie (2004) "perpustakaan adalah sebuah bangunan gedung yang isinya berupa buku-buku dan bahan bacaan lainnya serta berbagai sumber pengetahuan seperti film, chalet yang disediakan untuk dimanfaatkan oleh para pengguna.

d. Internet

Fasilitas internet pada perguruan tinggi dapat menunjang mahasiswa dalam proses belajar dan mencari informasi berkaitan dengan tugas perkuliahan.

\section{Kepuasan Mahasiswa \\ Definisi Kepuasan Mahasiswa}

Kepuasan adalah tingkat perasaan seseorang setelah mebandingkan kinerja (atau hasil) yang Ia rasakan dibandingkan dengan harapannya (Kotler, 2003). Kepuasan mahasiswa dipersepsikan sebagai faktor psikologis atau pendapat subjektif mahasiswa berdasarkan pengalaman dibandingkan dengan ekspektasi/harapan mahasiswa (educational). Konsep ini dapat didefinisikan dengan beberapa cara, seperti, kepuasan adalah overall feeling, atau attitude seseorang mengenai suatu layanan jasa setelah mengalaminya (Elliott dan Healy, 2001), atau dapat dipersepsikan sebagai evaluasi subjektif mahasiswa berdasarkan pengalamannya dengan edukasi dan kehidupan kampus (Elliot dan Shin, 2002).

\section{Indikator Kepuasan Mahasiswa}

Subrahmanyam (2016) mengemukakan indikator kepuasan mahasiswa meliputi :

$\checkmark$ Pelayanan Dosen

$\checkmark$ Peran staf administrasi untuk mengurus administrasi

$\checkmark \quad$ Ketersediaan fasilitas penunjang belajar pada perguruan tinggi

\section{KERANGKA PEMIKIRAN}

Berikut adalah kerangka pemikiran teoritis dalam penelitian ini yang ditunjukkan pada Gambar 2

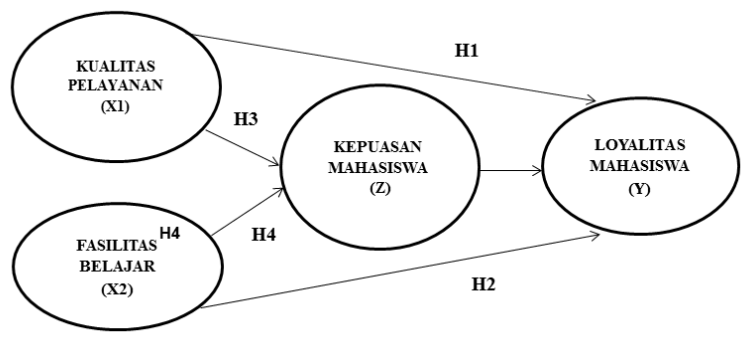

Gambar 1.1 Kerangka Pemikiran

\section{Hipotesis}

H1: Kualitas pelayanan berpengaruh positif dan signifikan terhadap loyalitas mahasiswa pada magister manajemen UPN 'veteran' Yogyakarta

$\mathrm{H} 2$ : Fasilitas belajar berpengaruh positif dan signifikan terhadap loyalitas mahasiswa pada magister manajemen UPN 'veteran' Yogyakarta

H3: Kualitas pelayanan berpengaruh positif dan signifikan terhadap loyalitas mahasiswa pada magister manajemen UPN 'veteran' Yogyakarta dimediasi kepuasan mahasiswa

H4: Fasilitas belajar berpengaruh positif dan siginifikan terhadap loyalitas mahasiswa pada magister manajemen UPN 'veteran' Yogyakarta dimediasi kepuasan mahasiswa.

\section{METODE PENELITIAN}

Rancangan yang digunakan dalam penelitian ini adalah pendekatan kuantitatif. Metode penelitian ini termasuk penelitian survei (Sugiyono, 2007). Penelitian ini merupakan penelitian asosiatif dan bersifat kausal. Obyek dalam penelitian ini adalah mahasiswa Magister Manajemen Univeristas Pembangunan Nasional "Veteran" Yogyakarta. Sedangkan waktu penelitian selama dua bulan. Pengumpulan data dalam menggunakan wawancara dan kuesioner. Data yang terkumpul akan diolah menggunakan alat analisis deskriptif dan kuantitatif. Teknik analisis yang digunakan untuk analisis data adalah Partial Least Square (PLS). Penelitian ini bertujuan untuk mengetahui pengaruh kualitas pelayanan dan fasilitas belajar terhadap loyalitas mahasiswa dimediasi kepuasan mahasiswa.

Populasi dalam penelitian ini adalah mahasiswa Magister Manajemen Universitas Pembangunan Nasional "Veteran" Yogyakarta yang masih kuliah. Penelitian ini akan mengambil sampel sebanyak 100 responden. Peneliti menggunakan metode non probability sampling dengan teknik purposive sampling. Kriteria pemilihan sampel dalam 
penelitian ini adalah 100 mahasiswa dari angkatan 28 -32 yang pernah berkuliah dan yang masih aktif kuliah di Magister Manajemen Universitas Pembangunan Nasional "Veteran" Yogyakarta. Jenis data penelitian adalah data primer.

Penelitian ini mengambil sampel sebanyak 100 responden. peneliti menggunakan metode non probability sampling dengan teknik purposive sampling. Nonprobability sampling adalah teknik yang tidak memberi peluang/kesempatan yang sama bagi setiap unsur atau anggota populasi untuk dipilih menjadi sampel. Kriteria pemilihan sampel dalam penelitian ini adalah 100 mahasiswa dari angkatan 28 -32 yang pernah berkuliah dan yang masih aktif kuliah di Magister Manajemen Universitas Pembangunan Nasional "Veteran" Yogyakarta.

Jenis data penelitian yang digunakan adalah data primer melalui kuesioner. Teknik pengumpulan data dalam penelitian ini menggunakan metode kuesioner/angket. Pengukuran setiap variabel-variabel ini menggunakan skala Likert lima point atau sering disebut skala ordinal karena pengukurannya menggunakan skala ordinal, Imam Ghozali, (2002:41). Dengan skala likert variabel yang akan diukur dijabarkan menjadi indikator variabel. Indikator tersebut dijadikan sebagai titik tolak untuk menyusun item-item instrumen yang dapat berupa pernyataan atau pertanyaan. Variabel dalam penelitian ini adalah Loyalitas Mahasiswa sebagai variabel dependen (Y), variabel Kualitas Pelayanan sebagai variabel independen (X1), variabel Fasilitas Belajar sebagai variabel (X2), dan Kepuasan Mahasiswa sebagai variabel mediasi $(\mathrm{Z})$.

\section{HASIL DAN PEMBAHASAN}

\section{A. HASIL PENELITIAN}

\section{Analisis Deskriptif}

Sebagain besar responden didominasi oleh respoden perempuan yaitu 52\% dengan frekuensi 52 orang. Selain itu, responden yang paling banyak berkuliah didominasi umur 26-28 tahun yaitu sebesar 34\% (34 orang).

\section{Analisis Kuantitatif}

Inner Model ( Model Struktural ) atau disebut juga dengan uji pengaruh / uji hipotesis.

Uji struktural (Inner Model) dilakukan setelah melalui uji indikator (Outer Model) yaitu uji Convergent Validity, Discriminant Validity, AVE, dan Composite Reliability. Setelah melalui uji tersebut, barulah hasil inner model dapat digunakan untuk melakukan analisis. Inner model meliputi : koefisien determinasi
(R2), Q2 predictive relevance, koefisien parameter dan T-statistik. Berikut adalah gambar hasil PLS Algorithm, untuk gambar hasil Bootstraping terlampir.

Gambar Model 4.1 Hasil PLS Algoritm

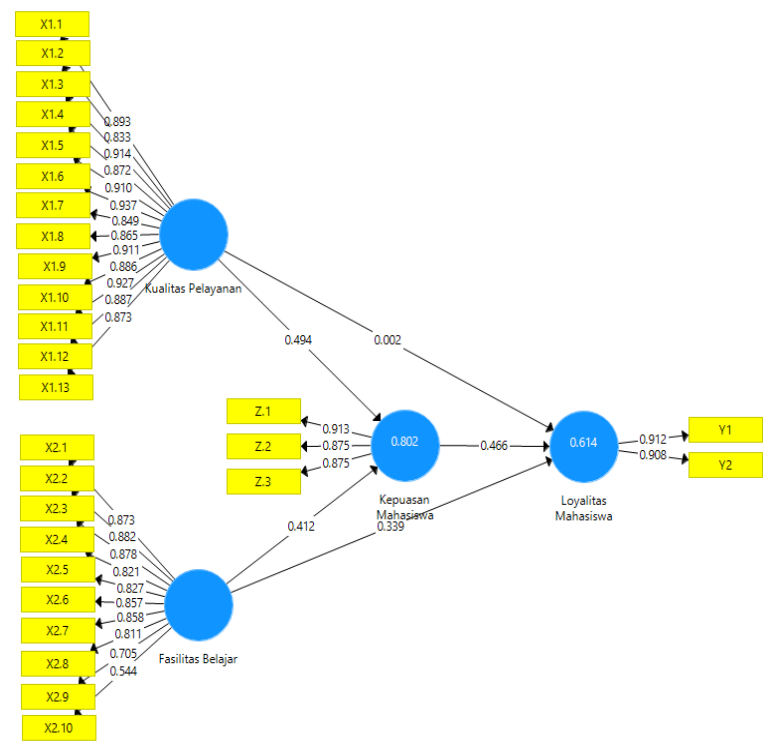

Penafsiran:

a. Koefisien determinasi (R2)

Menunjukkan bahwa Kepuasan Mahasiswa dipengaruhi oleh Kualitas Pelayanan dan Fasilitas Belajar sebesar $80,2 \%$ sisanya sebesar $19,8 \%$ dipengaruhi oleh faktor lain yang tidak terdapat dalam model. Sedangkan Loyalitas Mahasiswa dipengaruhi oleh Kualitas Pelayanan dan Fasilitas Belajar MM UPN 'V' Yk sebesar 61,4\%, sisanya $38,6 \%$ dipengaruhi oleh faktor lain yang tidak tedapat dalam model.

b. $\quad \mathrm{Q}$ - square predictive relevance $(\mathrm{Q} 2)$

Kualitas Pelayanan, Fasilitas Belajar dan Kepuasan Mahasiswa mempunyai pengaruh terhadap Loyalitas Mahasiswa sebesar 78,0\% dan sisanya $22,0 \%$ tidak dapat dideteksi oleh model dalam penelitian ini.

c. P-value

Variabel Fasilitas Belajar terhadap Loyalitas Mahasiswa memiliki Pvalue 0,226 > 0,05 dan Kualitas Pelayanan ke Loyalitas Mahasiswa memiliki Pvalue 0,994 > 0,05 dan tidak signifikan. Selain itu, pengaruh dari variabel eksogen dan endogen terhadap variabel endogen lainnya dinyatakan signifikan karena nilai PValue kurang dari 0,05 (signfikansi 5\%).

d. Koefisien parameter

Besarnya koefisien parameter dari pengaruh Kualitas Pelayanan terhadap Kepuasan Mahasiswa sebesar 0,494 . Artinya terdapat pengaruh positif antara Kualitas Pelayanan terhadap Kepuasan Mahasiswa. 
Hal ini dapat dikatakan bahwa semakin baik Kualitas Pelayanan maka akan semakin meningkatkan Kepuasan Mahasiswa Magister Manajemen Universitas Pembangunan Nasional 'Veteran' Yogyakarta.

Besarnya koefisien parameter dari pengaruh Kualitas Pelayanan terhadap Loyalitas Mahasiswa sebesar 0,002 artinya terdapat pengaruh positif Kualitas Pelayanan terhadap Loyalitas Mahasiswa. Hal ini dapat dikatakan bahwa semakin baik Kualitas Pelayanan maka akan semakin meningkatkan Loyalitas Mahasiswa Magister Manajemen Universitas Pembangunan Nasional 'Veteran' Yogyakarta.

Besarnya koefisien parameter dari pengaruh Fasilitas Belajar terhadap Kepuasan Mahasiswa sebesar 0,412 artinya terdapat pengaruh positif dari Fasilitas Belajar terhadap Kepuasan Mahasiswa. Hal ini dapat dikatakan bahwa semakin baik Fasilitas Belajar yang terdapat di Magister Manajemen Universitas Pembangunan Nasional 'Veteran' Yogyakarta maka semakin tinggi Kepuasan Mahasiswa.

Besarnya koefisien parameter dari pengaruh Fasilitas Belajar terhadap Loyalitas Mahasiswa sebesar 0,339 artinya terdapat pengaruh positif dari Fasilitas Belajar terhadap Loyalitas Mahasiswa. Hal ini dapat dikatakan bahwa semakin baik Fasilitas Belajar yang terdapat di Magister Manajemen Universitas Pembangunan Nasional 'Veteran' Yogyakarta maka semakin tinggi Loyalitas Mahasiswa Magister Manajemen Universitas Pembangunan Nasional 'Veteran' Yogyakarta.

Besarnya koefisien parameter dari pengaruh Kepuasan Mahasiswa terhadap Loyalitas Mahasiswa sebesar 0,466. Artinya terdapat pengaruh positif Kepuasan Mahasiswa terhadap Loyalitas Mahasiswa. Hal ini dapat dikatakan bahwa semakin tinggi Kepuasan Mahasiswa maka akan semakin meningkatkan Loyalitas Mahasiswa.

\section{e. Analisis Jalur}

Untuk analisis jalur dapat dilihat pada tabel dibawah ini. Smart PLS secara langsung menghasilkan output Path Coefficient (Indirect Effect).

Tabel 4.2 Indirect Effect

\begin{tabular}{|l|l|l|l|}
\hline Variabel & $\begin{array}{l}\text { Original } \\
\text { Sampel }\end{array}$ & $\begin{array}{l}\text { T- } \\
\text { Statistik }\end{array}$ & $\begin{array}{l}\text { P- } \\
\text { Value }\end{array}$ \\
\hline $\begin{array}{l}\text { Kualitas Pelayanan } \\
(\mathrm{X} 1) \rightarrow \text { Kepuasan }\end{array}$ & 0,231 & 2,088 & 0,033 \\
Mahasiswa (Z) $\rightarrow$ & & & \\
$\begin{array}{l}\text { Loyalitas Mahasiswa } \\
(Y)\end{array}$ & & & \\
\hline
\end{tabular}

\begin{tabular}{|l|l|l|l|}
\hline Fasilitas Belajar & 0,192 & 1,984 & 0,048 \\
$(\mathrm{X} 2) \rightarrow$ Kepuasan & & & \\
Mahasiswa (Z) $\rightarrow$ & & & \\
Loyalitas Mahasiswa & & & \\
$(Y)$ & & & \\
\hline
\end{tabular}

Sumber: Diolah dari output SmartPLS 3.0

\section{Uji Hipotesis}

Hipotesis 1 : Kualitas pelayanan berpengaruh positif dan signifikan terhadap loyalitas mahasiswa pada magister manajemen UPN 'veteran' Yogyakarta

$\mathrm{Ho}=$ Kualitas pelayanan tidak berpengaruh positif dan signifikan terhadap loyalitas mahasiswa pada magister manajemen UPN 'veteran' Yogyakarta.

$\mathrm{Ha}=$ Kualitas pelayanan berpengaruh positif dan signifikan terhadap terhadap loyalitas mahasiswa pada magister manajemen UPN 'veteran' Yogyakarta .

Berdasarkan tabel Path Coefficient, kualitas pelayanan secara langsung berpengaruh positif terhadap loyalitas mahasiswa sebesar 0,002 namun tidak signifikan karena T-statistic 0,008 < 1,96 dan Pvalue sebesar $=0,994>0.05$. Dengan demikian kualitas pelayanan tidak berpengaruh signifikan terhadap loyalitas mahasiswa Magister Manajemen Universitas Pembangunan Nasional 'Veteran' Yogyakarta. Hal ini menyatakan bahwa H0 diterima dan Ha ditolak.

Hipotesis 2: Fasilitas belajar berpengaruh positif dan signifikan terhadap loyalitas mahasiswa pada magister manajemen UPN 'veteran' Yogyakarta

Ho = Fasilitas belajar tidak berpengaruh positif dan signifikan terhadap loyalitas mahasiswa magister manajemen UPN 'veteran' Yogyakarta

$\mathrm{Ha}=$ Fasilitas belajar berpengaruh positif dan signifikan terhadap loyalitas mahasiswa pada magister manajemen UPN 'veteran' Yogyakarta.

Berdasarkan tabel Path Coefficient, fasilitas belajar berpengaruh positif terhadap loyalitas mahasiswa sebesar 0,339 namun tidak signifikan karena T-statistik 1,218 < 1,96 dan P-value sebesar = $0.226>0.05$. Dengan demikian fasilitas belajar tidak berpengaruh signifikan terhadap loyalitas mahasiswa Magister Manajemen Universitas Pembangunan Nasional 'Veteran' Yogyakarta. Hal ini menyatakan H0 diterima dan Ha ditolak.

Hipotesis 3: Kualitas pelayanan berpengaruh positif dan signifikan terhadap loyalitas mahasiswa pada magister manajemen UPN 'veteran' Yogyakarta dimediasi kepuasan mahasiswa

$\mathrm{H} 0=$ Kualitas pelayanan tidak berpengaruh positif dan signifikan terhadap loyalitas mahasiswa pada magister 
manajemen UPN 'veteran' Yogyakarta dimediasi kepuasan mahasiswa

$\mathrm{Ha}=$ Kualitas pelayanan berpengaruh positif dan signifikan terhadap loyalitas mahasiswa pada magister manajemen UPN 'veteran' Yogyakarta dimediasi kepuasan mahasiswa.

Kualitas pelayanan dalam hal ini berpengaruh positif dan signifikan terhadap loyalitas mahasiswa dengan mediasi kepuasan mahasiswa sebesar 0,231 ( T-Statistik $=2,088>1,96$ dan P-value sebesar $=0,033$ $<0,05)$. Hasil estimasi uji mediasi menunjukkan bahwa kepuasan mahasiswa dapat memediasi pengaruh kualitas pelayanan terhadap loyalitas mahasiswa karena T-statistik lebih besar dari 1,96 yaitu 2,088 dan P-value $=0,033$ lebih besar dari Pvalue 0,05 . Dapat diintepretasikan bahwa ada pengaruh kualitas pelayanan terhadap loyalitas mahasiswa yang dimediasi oleh kepuasan mahasiswa. Hal ini menyatakan $\mathrm{H} 0$ ditolak dan Ha diterima.

Hipotesis 4: Fasilitas belajar berpengaruh positif dan siginifikan terhadap loyalitas mahasiswa pada magister manajemen UPN 'veteran' Yogyakarta dimediasi kepuasan mahasiswa

$\mathrm{H} 0=$ Fasilitas belajar tidak berpengaruh positif dan siginifikan terhadap loyalitas mahasiswa pada magister manajemen UPN 'veteran' Yogyakarta dimediasi kepuasan mahasiswa

$\mathrm{Ha}=$ Fasilitas belajar berpengaruh positif dan siginifikan terhadap loyalitas mahasiswa pada magister manajemen UPN 'veteran' Yogyakarta dimediasi kepuasan mahasiswa

Fasilitas belajar dalam hal ini berpengaruh positif dan signifikan terhadap loyalitas mahasiswa dengan mediasi kepuasan mahasiswa sebesar 0,192 (TStatistik $=1,984$ dan P-value $=0,048$ ). Hasil estimasi uji mediasi menunjukkan bahwa kepuasan mahasiswa dapat memediasi pengaruh fasilitas belajar terhadap loyalitas mahasiswa karena T-statistik lebih besar dari 1,96 yaitu 1,984 dan $\mathrm{P}$-value $=0,048$ lebih kecil dari $\mathrm{P}$ value 0,05 . Dapat diintepretasikan bahwa ada pengaruh fasilitas belajar terhadap loyalitas mahasiswa yang dimediasi oleh kepuasan mahasiswa. Hal ini menyatakan $\mathrm{H} 0$ ditolak dan $\mathrm{Ha}$ diterima.Usaha menengah di Kabupaten Sleman dengan rata-rata memiliki penilaian yang tinggi terhadap kinerja dengan nilai rata-rata (mean) 3,40 yang berarti kinerja berada pada kategori tinggi. Hal ini menunjukkan tingginya kemampuan dari para pengelola usaha menengah dalam mengelola sumber daya yang ada sehingga dapat memberikan nilai kepada usaha menengah tersebut. Indikator usaha menengah yang memiliki pangsa pasar yang luas menunjukkan penilaian yang paling besar dengan rata-rata sebesar 3,96 .

\section{Pembahasan}

1. Kualitas pelayanan berpengaruh positif namun tidak signifikan terhadap loyalitas mahasiswa pada magister manajemen UPN 'Veteran' Yogyakarta (hipotesis pertama).

Hasil penelitian ini menunjukkan bahwa kualitas pelayanan secara langsung berpengaruh positif namun tidak berpengaruh signifikan terhadap loyalitas mahasiswa. Dalam penelitian ini yang dilakukan kepada 100 responden, diperoleh hasil ratarata responden mempunyai skor jawaban untuk kualitas pelayanan yaitu 4,16 yang menunjukkan bahwa kualitas pelayanan yang dirasakan mahasiswa MM UPN ' $V$ ' Yk berada pada kategori tinggi atau dengan kata lain kualitas pelayanan yang diberikan baik. Responden mempunyai persepsi bahwa kualitas pelayanan yang terdapat di MM UPN ' $V$ ' Yk seperti ketepatan waktu dosen hadir dalam perkuliahan, penguasaan materi perkuliahan, kesuaian materi ajar dosen dengan silabus perkuliahan, bimbingan dosen terhadap mahasiswa, respon dosen terhadap keluhan mahasiswa, kesediaan staf administrasi mengurus administrasi mahasiswa, keramahan dosen terhadap mahasiswa, keramahan staf administrasi terhadap mahasiswa, kemudahan menemui dosen di kampus, kesediaan dosen ditemui mahasiswa diluar kampus, kesigapan staf administrasi ketika dibutuhkan, kerapihan dosen dan kerapihan staf administrasi telah berpengaruh positif namun tidak signifikan dengan kata lain bahwa kualitas pelayanan belum secara langsung meningkatkan loyalitas mahasiswa MM UPN ' $V$ ' Yk. Penelitian ini mendukung penelitian yang dilakukan oleh Kusumawati, dkk (2013) Pengaruh Kualitas Pelayanan terhadap Loyalitas Pelanggan mendapat hasil tidak signifikan yaitu dengan besar P-Value 0,559>0,05.

Kesimpulannya bahwa loyalitas mahasiswa akan semakin tinggi apabila mahasiswa mendapatkan kualitas pelayanan yang lebih baik. Dengan kata lain, kualitas pelayanan yang diberikan pihak MM UPN ' $V$ ' Yk harus lebih ditingkatkan lagi agar secara langsung menimbulkan loyalitas yang tinggi pada mahasiswa.

\section{Fasilitas belajar berpengaruh positif namun tidak signifikan terhadap loyalitas mahasiswa pada magister manajemen UPN 'Veteran' Yogyakarta (Hipotesis kedua)}

Berdasarkan hasil analisis data menunjukkan bahwa fasilitas belajar terbukti memberikan pengaruh 
positif terhadap loyalitas mahasiswa namun tidak secara langsung berpengaruh signifikan terhadap loyalitas mahasiswa. Hal ini membuktikan bahwa fasilitas belajar yang ada di MM UPN ' $\mathrm{V}$ ' Yk belum mampu meningkatkan loyalitas mahasiswa. Dalam penelitian ini yang dilakukan kepada 100 responden, diperoleh hasil rata-rata responden mempunyai skor jawaban untuk fasilitas belajar yaitu 4,08 berada pada kategori tinggi. Hasil tersebut menunjukkan bahwa fasilitas belajar yang diwakilan pada indiktor kuesioner seperti kebersihan ruang kelas, kenyamanan ruang kelas, kebersihan ruang baca, kenyamanan ruang baca, ketersediaan alat tulis (spidol, penghapus), ketersediaan media belajar (proyektor, speaker), kebersihan perpustakaan, kenyamanan perpustakaan, ketersediaan buku referensi di perpustakaan dan kecepatan internet telah memberikan hasil yang baik hanya saja perlu ditingkatkan lagi agar secara langsung berpengaruh signifikan pada loyalitas mahasiswa. Penelitian ini sependapat dengan penelitian yang dilakukan oleh Ika Kusumawati (2015) yang mengatakan bahwa fasilitas tidak berpengaruh signifikan terhadap loyalitas pelanggan.

Oleh karena itu, fasilitas belajar pada MM UPN ' V' Yk yang baik harus dipertahankan serta perlu untuk ditingkatkan menjadi lebih baik agar dapat secara langsung menciptakan loyalitas mahasiswa terhadap MM UPN 'V' Yk.

\section{Kualitas pelayanan berpengaruh positif dan signifikan terhadap loyalitas mahasiswa pada magister manajemen UPN 'veteran' Yogyakarta dimediasi kepuasan mahasiswa (Hipotesis ketiga)}

Hasil analisis pengaruh kualitas pelayanan secara langsung terhadap loyalitas mahasiswa menunjukkan hasil yang positif namun tidak signifikan, akan tetapi ketika dimediasi oleh kepuasan mahasiswa hasilnya menjadi positif dan signifikan artinya kepuasan mahasiswa mampu memediasi kualitas pelayanan terhadap loyalitas mahasiswa di MM UPN 'V' Yk. Pengaruh tidak langsung kepuasan mahasiswa sepenuhnya memberikan kontribusi dalam meningkatkan loyalitas mahasiswa. Dalam penelitian ini yang dilakukan kepada 100 responden, diperoleh hasil rata-rata responden mempunyai skor jawaban untuk kualitas pelayanan yaitu 4,16 (kategori tinggi) dan kepuasan mahasiswa 4,05 (kategori tinggi). Hasil tersebut menunjukkan bahwa kualitas pelayanan MM UPN ' V' Yk berada pada kategori tinggi, dan kepuasan mahasiswa berada pada kategori tinggi. Persepsi responden bahwa kualitas pelayanan yang terdapat di MM UPN ' $V$ ' $Y k$ baik sehingga mahasiswa merasa puas akan terhadap pelayanan dosen, dan puas terhadap peran staf administrasi untuk mengurus administrasi di MM UPN 'V' Yk.

Hasil penelitian ini sejalan dengan penelitian Indra Lutfi Sofyan, Ari Pradhanawati, dan Hari Susanta Nugraha (2013) dimana penelitian mereka menyimpulkan bahwa variabel fasilitas, kualitas pelayanan dan kepuasan berpengaruh positif dan signifikan terhadap loyalitas.

4.Fasilitas belajar berpengaruh positif dan siginifikan terhadap loyalitas mahasiswa pada magister manajemen UPN 'Veteran' Yogyakarta dimediasi kepuasan mahasiswa (Hipotesis Keempat).

Hasil analisis pengaruh fasilitas belajar secara langsung terhadap loyalitas mahasiswa menunjukkan hasil yang positif namun tidak signifikan, akan tetapi ketika dimediasi oleh kepuasan mahasiswa nampak bahwa kepuasan mahasiswa sebagai mediasi mempunyai pengaruh positif dan signifikan terhadap loyalitas mahasiswa di MM UPN ' $V$ ' Yk. Pengaruh tidak langsung kepuasan mahasiswa terhadap loyalitas mahasiswa MM UPN ' $\mathrm{V}$ ' Yk telah memberikan kontribusi dalam meningkatkan loyalitas mahasiswa. Dengan demikian, kepuasan mahasiswa sebagai mediasi antara fasilitas belajar terhadap loyalitas mahasiswa mempunyai pengaruh yang kuat dalam meningkatkan loyalitas mahasiswa MM UPN ' $\mathrm{V}$ ' Yk.

Dalam penelitian ini yang dilakukan kepada 100 responden, diperoleh hasil rata-rata responden mempunyai skor jawaban untuk fasilitas belajar yaitu 4,08 (kategori tinggi) dan kepuasan mahasiswa 4,05 (kategori tinggi). Hasil tersebut menunjukkan bahwa fasilitas belajar dan kepuasan mahasiswa berada pada kategori tinggi. Persepsi responden bahwa fasilitas belajar yang ada di MM UPN ' $V$ ' Yk tergolong baik sehingga mahasiswa merasa puas terhadap fasilitas penunjang belajar mengajar yang sudah ada.

MM UPN 'V' Yk tentu selanjutnya perlu untuk tetap meningkatkan fasilitas belajar agar bias menjaga kepuasan mahasiswa dan pastinya untuk menambah rasa loyalitas mahasiswa terhadap MM UPN 'V' Yk. Dengan meningkatnya kepuasan mahasiswa sebagai akibat dari semakin baiknya fasilitas belajar yang ada maka mahasiswa akan semakin loyal pada MM UPN 'V' Yk. Hasil penelitian ini sejalan oleh penelitian Rianto Nurcahyo, Annisa Fitriyani, Irma Nur Hudda (2017) yang menunjukkan bahwa variabel fasilitas, kualitas layanan, dan kepuasan pelanggan secara signifikan mempengaruhi variabel loyalitas pelanggan. 
Kesimpulannya, fasilitas belajar yang baik dan memadai dan dimediasi oleh kepuasan mahasiswa yang tinggi mampu berpengaruh terhadap loyalitas mahasiswa MM UPN ' $\mathrm{V}$ ' Yk.

\section{A. Kesimpulan}

\section{KESIMPULAN DAN SARAN}

Berdasarkan hasil penelitian seperti yang telah diuraikan pada bab sebelumnya dapat ditarik beberapa kesimpulan yaitu :

1. Kualitas pelayanan berpengaruh positif namun tidak signifikan terhadap loyalitas mahasiswa pada MM UPN 'V' Yk.

2. Fasilitas belajar berpengaruh positif namun tidak signifikan terhadap loyalitas mahasiswa pada MM UPN ' $V$ ' Yk.

3. Kualitas pelayanan berpengaruh positif dan signifikan terhadap loyalitas mahasiswa pada MM UPN ' $\mathrm{V}$ ' $\mathrm{Yk}$ dimediasi kepuasan mahasiswa.

4. Fasilitas belajar berpengaruh positif dan signifikan terhadap loyalitas mahasiswa pada MM UPN ' $\mathrm{V}$ ' $\mathrm{Yk}$ dimediasi kepuasan mahasiswa.

\section{B. Saran}

1. MM UPN ' $\mathrm{V}$ ' $Y k$ perlu untuk meningkatkan kualitas pelayanan yang sudah ada sehingga dapat secara langsung meningkatkan loyalitas mahasiswa. Mahasiswa MM UPN ' $\mathrm{V}$ ' Yk loyal terhadap MM UPN ' $\mathrm{V}$ ' YK karena mereka merasa puas terhadap kualitas pelayanan yang sudah ada, untuk itu pihak MM UPN ' $\mathrm{V}$ ' $\mathrm{Yk}$ sebagai penyedia jasa harus meningkatkan mutu pelayanan sehingga menimbulkan kesan yang mendalam dalam diri mahasiswa yang langsung berdampak pada loyalitas mahasiswa terhadap kualitas pelayanan. Dengan adanya rasa loyalitas mahasiswa terhadap kualitas pelayanan akan berdampak pada sikap mahasiswa untuk mengatakan hal positif tentang MM UPN ' $\mathrm{V}$ ' Yk serta semakin banyak mengajak orang lain untuk berkuliah di MM UPN 'V' Yk. Untuk itu kualitas pelayanan yang ada di MM UPN ' $V$ ' $Y k$ seperti bimbingan dosen terhadap proses belajar mahasiswa serta peran staf administrasi dalam mengurus administrasi mahasiswa perlu untuk ditingkatkan lagi.

2. MM UPN ' $\mathrm{V}$ ' Yk juga perlu untuk meningkatkan dan menyediakan fasilitas belajar yang memadai bagi mahasiswa. Khususnya pada jaringan internet dimana hal tersebut juga sangat membantu dan menunjang mahasiswa untuk mendapatkan informasi dan materi untuk kelancaran proses belajar. Oleh sebab itu, MM UPN ' $\mathrm{V}$ ' Yk sebagai penyedia jasa layanan harus mampu untuk membuat mahasiswa loyal secara langsung dengan cara meningkatkan ketersediaan fasilitas belajar seperti memperbanyak ketersediaan buku referensi pada perpustakaan, serta menambah daya jaringan internet. Hal konkrit seperti itu dapat menimbulkan kesan yang positif dalam diri mahasiswa sehingga pada akhirnya mahasiswa semakin loyal terhadap MM UPN ' $\mathrm{V}$ ' Yk dan tidak ragu untuk mengajak saudara atau orang lain untuk berkuliah di MM UPN 'V' Yk.

\section{REFERENSI}

[1] A. Parasuraman, Valarie A. Zeithaml, and Leonard L. Berry. 1988.

[2] "SERVQUAL: A Multiple-Item Scale for Measuring Consumer Perceptions

[3] of Service Quality”. Journal of Retailing. Vol 64 (1) pp 12-37

[4] Aaker, David A. Kumar, V. Day, George S. 2007. Marketing Research. 9th Edition. John Wiley \& Sons. Danvers.

[5] Amstrong, dan Kotler. 2003. Dasar-dasar Pemasaran. Jilid 1. Edisi Kesembilan. Penerbit PT. Indeks Gramedia, Jakarta.

[6] Azwar, Saifuddin. 2003. Metode Penelitian. Yogyakarta: Pustaka Pelajar.

[7] Basir Barthos. 1997. Manajemen Kearsipan untuk Lembaga Negara, Swasta, dan

[8] Perguruan Tinggi. Jakarta : Bumi Aksara.

[9] Birkinshaw, J., and Mol, M.J. 2008. Academy of Management Review. Vol.33. No.4 82s$84 \mathrm{~s}$.

[10] Bitner, Mary Jo, Zeithaml, Valarie A, (1996). Services Marketing. Edisi1.Boston. MCGrawHill

[11] Bitner, M. J. dan Zeithaml, V. A. 2003. Service Marketing. 3rd ed. Tata McGraw Hill. New Delhi.

[12] Brameld, Theodore. 1992. Dasar Konsep Pendidikan Moral. Bandung:

\section{[13] ALFABETA}

[14] Chan, L.K., Hui,Y.V., Lo, H.P., Tse, S.K., Tso, G.K.F. and Wu, M.L. 2003. Consumer satisfaction index: new practice and findings. 
European Journal of Marketing. 37(5/6). 872909.

[15] Chin, W. W. 1998. The partial least squares approach for structural equation modeling. in G. A. Marcoulides. (Ed.), Modern methods for business research (pp.295-236). London: Lawrence Erlbaum Associates.

[16] Chun, R. 2005. Corporate reputation: Meaning and measurement. International Journal of Management Reviews, 7(2), 91-109.

[17] Darmawan, Deny. 2013. Metode penelitian kuantitatif. PT Remaja Rosdakarya.

[18] Departemen Pendidikan Nasional, 2003. Undang-Undang Nomor 20 Tahun 2003. Tentang Sistem Pendidikan Nasional, Jakarta: Depdiknas.

[19] Elliott, K.M. and Healy, M.A. 2001. Key factors influencing student satisfaction related to recruitment and retention. Journal of Marketing for Higher Education. 10(4), 1-11.

[20] Elliott, K.M. and Shin, D. 2002. Student Satisfaction: An alternative approach to assessing this important concept. Journal of Higher Education Policy and Management. 24(2), 197-209.

[21] Ellys Cornelia S, Nancy Veronica S. 2008. Analisa Pengaruh Kualitas Layanan terhadap Loyalitas Pelanggan di Laundry 5 Asec Surabaya. Jurnal Manajemen Perhotelan. Vol 4, No. 2, Hal 45-57.

[22] Engel, J. F., Blackwell, R. D., \& Miniard, P.W. 1995. Consumer Behavior. Eight edition. Orlando: The Dryden Press.

[23] Erik Nesset. 2007. Images, Satisfaction and Antecedents: Drivers of Student Loyalty? A Case Study of a Norwegian University College. Corporate Reputation Review. Vol. 10. No. 1.pp. $38-59$.

[24] Geta Ambartiasari, A. Rahman Lubis, dan Syafruddin Chan. 2017. Pengaruh kualitas pelayanan, kepercayaan dan Fasilitas kampus terhadap kepuasan dan dampaknya Kepada loyalitas mahasiswa politeknik Indonesia Venezuela. Jurnal Manajemen dan Inovasi. Vol. 8. No. 3. Oktober 2017: 12-23.

[25] Ghozali, Imam (2002). Aplikasi Analisis Multivariat dengan Program SPSS. Semarang:

[26] Badan Penerbit Universitas Diponegoro.
[27] Henry Taneo, Djuni. 2015., "Pengaruh Kualitas Layanan Terhadap Citra Perusahaan dan Loyalitas Pasien Rawat Inap di Rumah Sakit Panti Rapih Yogyakarta, Yogyakarta.

[28] Hamalik, Oemar. 2003. Proses Belajar Mengajar. Jakarta : Bumi Aksara.

[29] I Gede Mahatma Yuda Bakti dan Sik Sumaedi. 2012. An analysis of library customer loyalty "The role of service quality and customer satisfaction, a case study in Indonesia. Library Management. Vol. 34 No. 6/7. pp. 397-414.

[30] Ika Kusumawati. 2017. Pengaruh Kualitas Produk Dan Layanan Terhadap Loyalitas Pelanggan Coffee Shop. LIP FEB-UMM

[31] Ikhsan dan Misri. 2012. metode penelitian untuk manajemen, akuntansi dan bisnis. Cipta pustaka Media Perintis.

[32] Indra Lutfi Sofyan, Ari Pradhanawati, dan Hari Susanta Nugraha. 2013. Pengaruh Fasilitas dan Kualitas Pelayanan Terhadap Loyalitas, Melalui Kepuasan Konsumen Sebagai Variabel Intervening pada Star Clean Car Wash Semarang. Diponegoro Journal Of Social And Politic. Hal. 1-12

[33] Jogiyanto. 2009. Analisis dan Desain Sistem Informasi. Yogyakarta: Andi Offset.

[34] Joko. Riyadi. 2004, Gerbang Pemasaran, Penerbit Gramedia, Jakarta.

[35] Kotler, Philip (2003), Manajemen Pemasaran, Edisi 11 Jilid 1, Jakarta : PT

[36] Prenhallindo.

[37] Muhroji dkk. 2004. Manajemen Pendidikan. Surakarta : UMS Press.

[38] Oliver, R.L. 1980. A cognitive model of the antecedents and consequences of satisfaction decisions. Journal of Marketing Research. 17, 460-469.

[39] Oliver, R.L. .1997. Satisfaction: A Behavioral Perspective On The Consumer, McGraw-Hill, New York.

[40] Oliver, R.L. 1999. Whence consumer loyalty? Journal of Marketing, 63 (Special Issue 1999), 33-44.

[41] Rianto Nurcahyo, Annisa Fitriyani, Irma Nur Hudda. 2017. The Influence of Facility and Service Quality towards Customer Satisfaction and Its Impact on Customer 
Loyalty in Borobudur Hotel in Jakarta. Binus Business Review, 8(1), 23-29.

[42] Satiti Novita. 2015. Pengaruh Variabel Kualitas Layanan, Fasilitas Institusi Dan Organisasi Kemahasiswaan Terhadap Kepuasan Dan Loyalitas Mahasiswa Fakultas Ekonomi \& Bisnis Umm. EKOBIS - Ekonomi Bisnis Vol. 22, No. 2.

[43] Schneider, Mark. 2002. Do school facilities affect Academic Outcomes. National

[44] Clearinghouse For Educational Facilities.

[45] Selnes, F. 1993. An examination of the effects of product performance on brand reputation, satisfaction and loyalty. European Journal of Marketing, 27(9),19-35.

[46] Solomon, M.R. 1994. Consumer Behavior. 2nd edn. Allyn and Bacon, Needham Heights, MA, USA.

[47] Solomon, Michael R. 2011. Consumer behavior: buying habing, and being 9th Ed. New Jersey, USA: Pearon Prentice Hall

[48] Subrahmanyam Annamdevula. 2016. The effects of service quality on student loyalty: the mediating role of student satisfaction. Journal of Modelling in Management. Vol. 11 No. 2, 2016 pp. 446-462.

[49] Sugiyono. 2002. Metode Penelitian Bisnis. Bandung: Alfabeta.

[50] Sugiyono. 2006. Metode Penelitian Kuantitatif, Kualitatif dan R \& D. Bandung: Alfabeta.

[51] Sugiyono. 2007. Metode Penelitian Kuantitatif, Kualitatif dan R \& D. ALFABETA.
[52] Sugiyono 2016. Statistika untuk penelitian. Alfabeta. Bandung

[53] Sulastiyono, Agus. 2011. Manajemen Penyelenggaraan Hotel. Bandung: Alfabeta.

[54] Taylor, S. A., Celuch, K., \& Goodwin, S. 2004. The importance of brand equity to customer loyalty. Journal of product \& brand management. 13(4), 217-227.

[55] Tjiptono, Fandy. 2002. Strategi Pemasaran, Yogyakarta: Penerbit Andi .

[56] Tjiptono, Fandy. 2014. Pemasaran Jasa. Jakarta: Gramedia Cawang.

[57] The Liang Gie. 2002. Cara belajar efisien I, Yogyakarta : PUBIB

[58] Wendri, Rusli, 2011, Pengaruh Merek dan Citra Diri Terhadap Kepuasan Konsumen Produk Telepon Seluler Di Kotamadya Yogyakarta, Vol 6, No. 1, 43-53

[59] Zeithaml dan Bitner, 2000. Service Marketing: Integrating Customer Focus Across. The Firm, me Graw Hill.

[60] Zeithaml,V.A., Berry, L.L. and Parasuraman, A. 1996. The behavioral consequences of service quality. Journal of Marketing. 60(April), 31-46.

[61] Zeithaml, V.A. Bitner MJ. 1996. Delivering and Performing Service. Part Five.

[62] Service Marketing International Ed. The McGraw-Hill Inc. 